BMJ Open

Sport \&

Exercise

Medicine

\title{
Injury incidence in a Premier League youth soccer academy using the consensus statement: a prospective cohort study
}

\author{
Andrew Renshaw, ${ }^{1}$ Peter C Goodwin ${ }^{2}$
}

To cite: Renshaw A, Goodwin PC. Injury incidence in a Premier League youth soccer academy using the consensus statement: a prospective cohort study. BMJ Open Sport Exerc Med 2016;2:e000132.

doi:10.1136/bmjsem-2016000132

- Prepublication history and additional material is available. To view please visit the journal (http://dx.doi.org/ 10.1136/bmjsem-2016000132).

Accepted 25 September 2016

CrossMark

${ }^{1}$ Liverpool Football Club Academy, Liverpool, UK ${ }^{2}$ Department of Health Professions, Manchester Metropolitan University, Manchester, UK

Correspondence to Dr Peter C Goodwin; p.goodwin@mmu.ac.uk

\section{ABSTRACT}

Background: There is an established risk of injury to young athletes exposed to high training loads. Identifying and monitoring injury risk is essential to aid prevention. The aim of this study was to use the consensus statement to determine the incidence and pattern of injury in 1 English Premier League soccer academy during 1 season.

Methods: A prospective cohort study included 181 elite academy soccer players during the 2012-2013 season. Players were divided into 5 age groups between 9 and 18 years. The number, type and incidence of injuries were recorded during matches and training. Incidence was calculated per 1000 hours of exposure.

Results: 127 injuries occurred during 29346 hours of soccer exposure. $72 \%$ of injuries were non-contact related. Under (U)18 players sustained the highest number of match injuries. U12-14 players sustained the highest number of training injuries and injuries overall. U16 players sustained the highest number of severe injuries, and U18 players sustained the highest number of moderate injuries. U18 players sustained the highest number of injuries/ 1000 hours of training and overall. U15 players sustained the highest number of injuries/1000 hours of matches, the highest number of recurrent injuries and the highest incidence of recurrence. The most common injuries were muscle injuries in U15 and U18 players. The most common injury location was the anterior thigh, with the majority of these occurring in training.

Conclusions: Using the consensus statement, this study used a repeatable method to identify the injury profile of elite academy-level soccer players.

\section{BACKGROUND}

The governing bodies of soccer, Federation Internationale de Football Association (FIFA) and the Union of European Football Associations (UEFA), have expressed their concerns regarding the high demands on adult professional soccer players and the risks these demands pose in terms of injury. ${ }^{1}{ }^{2}$ Also of concern are the risks to

\section{What are the new findings?}

- The majority of injuries were sustained during training $(50 \%$ during training; $32 \%$ during matches and $17.3 \%$ were of unknown origin) although injury incidence was higher in matches.

- Older players were at higher risk and had greater odds of sustaining an injury during matches than training, whereas younger players had a higher risk and greater odds of sustaining an injury during training.

- Injury incidence during matches was highest for under 15 players (80/1000 hours) compared with the other age groups and was difficult to fully explain.

- The most common site of injury was the anterior thigh.

How might it impact on clinical practice in the near future?

- These data provide medical staff at Elite Soccer Academies with information with which to observe and predict potential injuries.

- The methodology provides a means by which comparisons might be made between injuries sustained among elite adult and youth soccer players.

- Clinicians should be on the lookout for increased injury incidence in those players who might not be match fit or play in higher age groups.

academy-level soccer players exposed to high training loads and a developing musculoskeletal system. The Football Association (FA) have expressed the need to monitor injury risk and prevention in order to maximise the time spent training and improving skill levels. $^{3-5}$

In monitoring training loads and injury risk, two problems have emerged: what to monitor and how to report the findings. The English Premier League began the Elite Player Performance Plan in $2012^{6}$ to "create 
more time for players to play and be coached'. However, increased training time, in addition to competitive play, increases the training load and could increase the risk of injury. No assessment of this increase in coaching time, in terms of its impact on injury, has been made so far.

A consensus statement was devised to standardise definitions, methodology, implementation and reporting standards that should be adopted for football injury studies. ${ }^{7}$ The FIFA Medical Assessment and Research Centre (F-MARC) introduced an Injury Consensus Group that devised the statement through a consensus model approach. ${ }^{7}$ The statement provides a minimum standard for transparency and reliability in sports injury research.

Injury within adult soccer is widely documented, although methodological inconsistencies make comparisons difficult. Research suggests that it is important to monitor injuries sustained in training as well as in matches. ${ }^{8-12}$ Preconsensus statement, adult match injury incidence ranged from 12 to $41.8 / 1000$ hours and training between 1.5 and 7.6/1000 hours of exposure. ${ }^{9} 1314$ Using the consensus statement ${ }^{7}$ researchers have reported match injury incidence between 24 and 30/ 1000 hours of exposure and training between 3 and 5/ 1000 hours of exposure. ${ }^{115}$

Research at youth level (not using the consensus statement) ${ }^{7}$ shows match and training injury incidence as similar to adult data, varying between 7.2 and 38.4/ 1000 hours of match exposure, and 3.6 and 7.2/ 1000 hours of training exposure. ${ }^{16-20}$ Research has also suggested that injury incidence increases with chronological age ${ }^{182122}$ and that increased training and match time increases injury risk among players. ${ }^{3} 23$

The aim of this study was to use the consensus statement methodology ${ }^{10}$ to describe injury incidence patterns and risk, according to commonly used age groups, in a UK Premier League soccer academy. Describing injury according to a standardised methodology will provide data that will both increase the current knowledge base within the subject area, while also assisting to reduce injuries within specific age groups.

\section{METHODS}

\section{Study design and population}

This was a prospective cohort study including all registered players at one English Premier League Football academy aged 9-18 years during the 2012-2013 season. Study methods and definitions reflect the consensus statement. ${ }^{10}$ In order to improve on previous methodologies within youth soccer ${ }^{5} 2324$ participants were grouped related to training/match exposure time. This study is reported in line with the Strengthening the Reporting of Observational Studies in Epidemiology (STROBE) statement. ${ }^{25}$

Players joining/leaving the cohort were included/ excluded from the date of joining/leaving, ensuring exposure and/or injury data were collected and included for analysis. ${ }^{7}$ All players were provided with off- season fitness programmes and were tested at the start of preseason training to provide a baseline. Players with an injury at the start of the study were excluded. International training and match exposure was not recorded. Ethical approval was obtained from Manchester Metropolitan University.

\section{Recording of injury and exposure data}

Two of the medical team (physiotherapists PS and AR) documented injuries using the Injury Record Form (Ekstrand (personal communication). Form taken from: The Study Manual: The English Premier League Injury Audit 2011-2014; see online supplementary appendix). It was amended to record an injury sustained to the anterior or posterior thigh, and also now classifies 'standard of play' and 'training group' when injured. ${ }^{15}{ }^{26}$ To increase standardisation between data collectors, a list of definitions was present with each injury record during data collection.

Details of training and match exposure time were documented by team coaches using a web-based system. ${ }^{27}$ Player exposure reports were emailed to the author (AR) and calculated on a monthly basis. Computers storing data were password protected and only the coaches and medical staff had access to the data.

\section{Pilot}

A pilot was carried out on five injuries sustained in April and May 2012. Injury Record Forms were completed on the same injured players by the two staff to determine reliability. No differences were found between the two records completed, as a result, no changes were made to the Injury Record Form.

\section{Data analysis}

Data were recorded and analysed in MS Excel. Injury incidence for matches, training, match and training combined was calculated per 1000 hours of exposure. Incidence was calculated by dividing the $\mathrm{N}$ of injuries per group by the hours exposed per group, multiplied by $1000 .^{7}$ Risk was included in the analysis to fully explore the injuries. ${ }^{28}$ Risk was calculated by dividing the number of injured players by the number of noninjured players, then dividing that by the hours of exposure multiplied by $1000 .^{7}$ Relative risk or risk ratio (RR) was calculated as the ratio of the risk of injury in matches to the risk of injury in training. ${ }^{29}$ The RR was standardised across age groups by using the number of injuries and non-injuries per 1000 hours. OR was calculated as the odds that an injury will occur in either match or training, compared with the odds of no injury occurring in either match or training. ${ }^{30}$ Standardised $\mathrm{RR}$ and OR allowed the observation of dose-response differences between age groups. ${ }^{31}$ The $95 \%$ CI was included for the RR and OR; a value of 1 is indicative that the estimated risks in both groups are the same. ${ }^{30}$ 


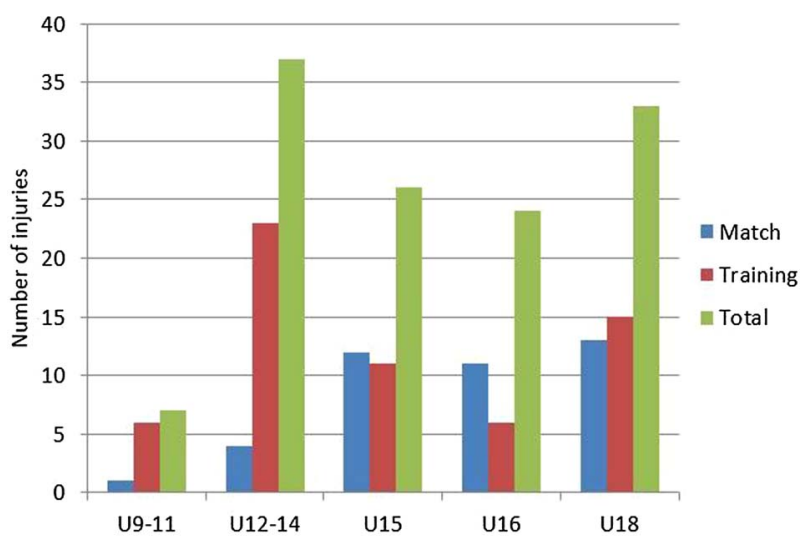

Figure 1 Number of injuries according to age group during one season in a Premier League soccer academy. $U$, under.

\section{RESULTS}

One hundred and eighty-one players were followed throughout the 2012/2013 season. Academy players were divided into age groups: under (U) 9-11 ( $n=68)$, U12-14 (n=59), U15 ( $\mathrm{n}=17)$, U16 $(\mathrm{n}=17)$, U18 $(\mathrm{n}=20)$ according to exposure time.

\section{Player injuries}

The total number of injuries sustained over the 2012/ 2013 season was $\mathrm{n}=127 ; 50 \%(\mathrm{n}=64)$ during training and $32 \%(n=41)$ during matches. Seventeen per cent $(n=22)$ were of unknown origin where players could not confirm when their symptoms first began. During matches, U18 players sustained $32 \%$ of injuries over the season $(n=13)$ compared with the U9-11 players who sustained 2\% $(n=1)$. U15 players sustained more match injuries than the older, U16 group. During training, U12-14 players sustained $38 \%$ of injuries $(n=23)$ compared with the U9-11 and U16 players who sustained $10 \%(\mathrm{n}=6$; figure 1$)$.

\section{Player injury incidence}

Injury incidence during matches was greatest in U15 players $(80 / 1000$ hours $)$ compared with other age groups. It was more than double that of U16 players (32/1000 hours) and 80 times more than U9-11 players $(0.39 / 1000$ hours). Injury incidence during training was greatest in U18 players (6/1000 hours) and lowest in U9-11 players (0.69/1000 hours; figure 2).

\section{Injury recurrence}

There were no recurrent injuries in the U9-11 group. $\mathrm{N}=8$ recurrent injuries were sustained across the remaining groups, equating to $6 \%$ of all injuries sustained. Fifteen per cent of injuries sustained in the U15 group were recurrences. Incidence of injury recurrence was highest in U15 players (1.05/1000 hours), followed by U16 (0.54/1000 hours), U18 (0.33/1000 hours) and U12-14 players $(0.14 / 1000$ hours $)$.

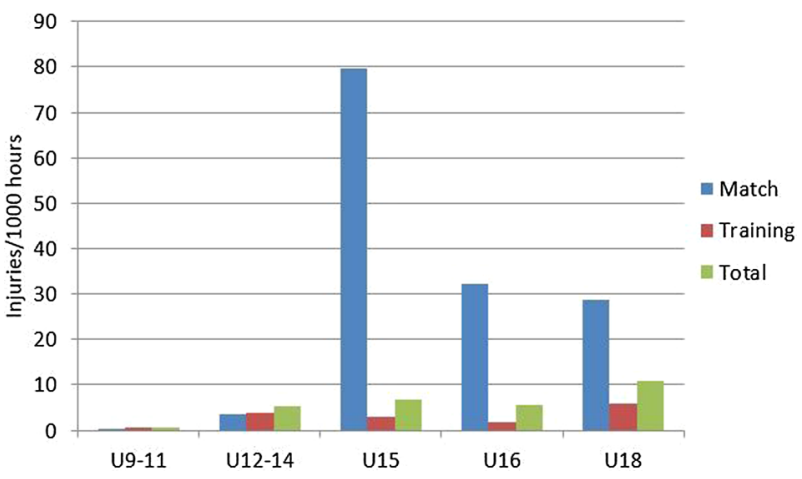

Figure 2 Injury incidence (injuries/1000 hours) according to age group during one season in a Premier League soccer academy. U, under.

\section{Injury severity}

The majority of injuries in each age group were of moderate severity. Sixty-seven per cent of injured players returned to play between 8 and 28 days after an absence from training/playing across all age groups. Ekstrand et $a l^{26}$ reported moderate injuries accounting for $37 \%$ of all injuries sustained. Severe injuries (return to training $>28$ days) accounted for $26 \%$ of all injuries sustained in comparison to $16 \%$ reported by Ekstrand et al. ${ }^{26}$ The remaining $7 \%$ of injuries were classified as mild or minor (return to training between 0 and 7 days).

\section{Injury location}

In agreement with previous studies, ${ }^{1} \quad \begin{array}{llllllll}5 & 12 & 14 & 16 & 18 & 26 & 32 & 33\end{array}$ the most common injury location was anterior thigh $(n=27,21 \%$; table 1$)$, followed by knee $(n=22,17 \%)$, and posterior thigh $(\mathrm{n}=17,13 \%)$. U12-14 players experienced the highest number of knee injuries $(n=8,36 \%)$; and U15 players sustained the most hip/groin injuries $(n=6,38 \%)$.

The greatest number of injuries occurred during training $(49 \%)$ compared with $32 \%$ during matches. The remaining $19 \%$ of injuries were reported in the days posttraining and matches where players could not confirm when their symptoms first began. The greater number of injuries in U12-14 players compared with U18 players is explained by the greater number of U12-14 players.

The RR and OR per 1000 hours of exposure of injury between match and training for each age group is shown in table 2. Indications are that the U16 and to a lesser extent the U15 players were at higher risk and had greater odds of sustaining an injury during a match than training. However, the $95 \%$ CI for these age groups is wide and span 1, indicating that this does not reach statistical significance. U9-11, U12-14 and U18 players were at greater risk and had greater odds of sustaining an injury during training. Only the $95 \%$ CI for the U12-14 players does not span 1, therefore reaching significance.

\section{Injury type}

Seven-two per cent of all injuries sustained were noncontact related. Most common injury types were muscle 
Table 1 Injury number and location by age group

\begin{tabular}{|c|c|c|c|c|c|c|c|c|c|c|c|}
\hline \multirow[b]{3}{*}{ Injury location } & \multicolumn{11}{|c|}{ Number of injuries according to age group } \\
\hline & \multicolumn{2}{|c|}{$\begin{array}{l}\text { U9-11 } \\
(n=68)\end{array}$} & \multicolumn{2}{|c|}{$\begin{array}{l}\text { U12-14 } \\
(n=59)\end{array}$} & \multicolumn{2}{|c|}{ U15 (n=17) } & \multicolumn{2}{|c|}{ U16 ( $(n=17)$} & \multicolumn{2}{|c|}{ U18 ( $n=20)$} & \multirow[b]{2}{*}{ Tota } \\
\hline & $\bar{M}$ & $\mathbf{T}$ & $\bar{M}$ & $T$ & $\overline{\mathbf{M}}$ & $\mathbf{T}$ & $\bar{M}$ & $\mathbf{T}$ & $\overline{\mathbf{M}}$ & $\mathbf{T}$ & \\
\hline \multicolumn{11}{|l|}{ Neck/cervical spine } & 1 \\
\hline Shoulder/clavicle & & & 1 & & & 1 & & & & & 2 \\
\hline \multicolumn{12}{|l|}{ Upper arm } \\
\hline \multicolumn{12}{|l|}{ Stern/rib/upper back } \\
\hline \multicolumn{12}{|l|}{ Elbow } \\
\hline \multicolumn{12}{|l|}{ Forearm } \\
\hline Wrist & & 1 & & 3 & & & & & & & 4 \\
\hline Hand/finger/thumb & & & & 1 & & & & & & (1) & 2 \\
\hline Abdomen & & & & & & 1 & 1 & (1) & & & 3 \\
\hline Lower back & & & & & & & 1 & (1) & 1 & & 3 \\
\hline Pelvis & & & & & & & & (1) & & & 1 \\
\hline Hip/groin & & 1 & & 4 & 1 & $3(2)$ & 1 & $1(1)$ & 1 & 1 & 16 \\
\hline Anterior thigh & & 2 & 1 & $6(1)$ & 3 & 2 & 2 & 1 & 2 & $6(1)$ & 27 \\
\hline Posterior thigh & & & & 5 & 2 & 2 & 1 & & 3 & $3(1)$ & 17 \\
\hline Knee & & 2 & 1 & $1(6)$ & 2 & 2 & & (2) & 2 & $2(2)$ & 22 \\
\hline Lower leg/Achilles & & & & $1(2)$ & & (1) & 1 & 1 & 1 & & 7 \\
\hline Ankle & 1 & & 1 & 2 & 4 & & 2 & 1 & 3 & 3 & 17 \\
\hline Foot/toe & & & & (1) & & & 1 & $2(1)$ & & & 5 \\
\hline Total & 1 & 6 & 4 & $23(10)$ & 12 & $11(3)$ & 11 & $6(7)$ & 13 & $15(5)$ & 127 \\
\hline
\end{tabular}

strain/rupture $(n=58,46 \%)$, ligament sprain/rupture $(n=20,16 \%)$ and tendon injuries $(n=16,13 \%)$. The most common injury subtypes were anterior thigh strains $(\mathrm{n}=27,21 \%)$ and knee $(\mathrm{n}=22,17 \%)$, most commonly occurring in the U18 group $(n=9,33 \%)$ and U12-14 $(\mathrm{n}=8,36 \%)$ age groups, respectively.

\section{DISCUSSION}

The aim of this study was to use the consensus statement ${ }^{7}$ methodology to describe the incidence, patterns and risk of injury according to commonly used age groups in a UK Premier League soccer academy.

The English Premier League introduced the Elite Player Performance Plan in $2012^{6}$ to 'create more time for players to play and be coached'. Its impact on training load and potential risk of injury from the increased training time, in addition to competitive play has not been assessed until now.

Research has suggested that improved levels of strength, endurance and coordination in older players might give rise to reduced injury levels when compared with younger age groups. ${ }^{27}$ We did not find this in the current study. Training injury incidence in all players shows similarities to those found within both elite adult (3-6/1000 hours) $)^{10} \quad 12 \quad 14 \quad 15 \quad 26$ and elite youth soccer (3.6-7.2/1000 hours). ${ }^{13} 18$ Training injury incidence for the U9-16 players is below that previously reported, possibly suggesting adequate levels of strength, endurance and coordination.

With regard to match injury incidence, we found 80/ 1000 hours in the U15 players to be higher than all other groups investigated within the current study, as well as elite adult and youth players included in other

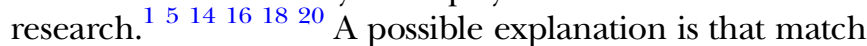
exposure for U15 players was substantially lower than other groups, explained by the lack of a games programme provided for this age group by the Premier League in the 2012-2013 season. However, while the U16 and to a lesser extent the U15 players had a higher risk and had greater odds of sustaining an injury during a match than training, the U16 players had three times

Table 2 RR and OR of injury per 1000 hours of exposure between match and training according to age group

\begin{tabular}{llllll}
\hline & U9-11 & U12-14 & U15 & U16 & U18 \\
\hline $\mathrm{RR}(95 \% \mathrm{Cl})$ & $\mathbf{0 . 1 7}(0.01$ to 13.80$)$ & $\mathbf{0 . 1 7}(0.06$ to 0.60$)$ & $1.09(0.57$ to 2.44$)$ & $1.83(0.55$ to 4.90$)$ & $0.87(0.60$ to 1.40$)$ \\
$\mathrm{OR}(\mathbf{9 5 \%} \mathrm{Cl})$ & $\mathbf{0 . 1 5}(0.02$ to 4.90$)$ & $\mathbf{0 . 1 1}(0.03$ to 0.71$)$ & $1.31(0.26$ to 10$)$ & $3.36(0.42$ to 17.53$)$ & $0.62(0.12$ to 3.61$)$ \\
\hline RR, relative risk; $\mathrm{U}$, under. & & &
\end{tabular}


more odds of getting injured in a match rather than training. Interestingly, we found trends indicating that younger players have a higher risk and greater odds of sustaining an injury in training while older players have a higher risk and greater odds of sustaining an injury during matches.

Our findings are in contrast to Malina ${ }^{34}$ who suggested that boys younger than 14 years of age were at most risk of injury in training and matches. It could be that fewer games put U15 players at a higher injury risk. Fewer games would result in the real-life experience which result in greater levels of muscle strength, power and coordination, also referred to as 'match fitness', which might reduce injury risk. ${ }^{20} \mathrm{~A}$ lack of match fitness might lead to local muscle fatigue and central brain fatigue, ${ }^{26} 33$ which also might be causative factors for match injuries; such factors are not yet suggested as an area of data collection within the consensus statement. ${ }^{7}$

An alternative hypothesis is that throughout the season, U15 players were required to play in U16 matches. Younger players being involved in competitive matches where their opponents are older and possibly more skeletally mature and able to cope with higher physical demands might explain a higher match injury incidence in the U15 group. In the current study, the skeletal maturity of the academy players was not tested; further research is needed to determine if grouping players according to this parameter is more relevant than by age. It could also be due to lower skill levels of players that might reduce protection from matchincurred injury. ${ }^{18}$ Such claims are not evidence based. While this might be a possibility for the results found, further research is necessary. The issue of players playing in multiple age groups is one which has not needed to be addressed in adult research.

Previous authors ${ }^{1} 14152633$ have suggested posterior thigh muscle strains were the most common injuries in adult soccer. We found the most common injury to be anterior thigh and knee injuries in academy players, suggesting as indicated in previous research, ${ }^{18}$ that growth-related factors such as hypermobility syndrome, Osgood-Schlatter disease, Severs disease and SindingLarsen disease might contribute to the larger number of training injuries. It is possible that growth-related injuries may account for the large number of knee injuries found among youth-level players.

Le Gall et $a l^{18}$ suggested that the U14 age group were the most likely to suffer injuries as a result of training. We found the highest number of injuries in training to be in U12-14 players. They had the second highest injury incidence in training and risk of injury per 100 hours of exposure, second to the U18s. The numbers of hip/groin injuries are noticeably higher within the U12-14 and U15 groups, with injury numbers reducing with advancing age beyond this age group. Recent research has suggested that anterior groin pain in these age groups may be indicative of femoroacetabular impingement, diagnosed via a detailed history, physical examination and radiographs. ${ }^{35}$
Our results showed a greater number of injuries sustained in training (50\%) than matches $(32 \%)$. The majority of studies suggest that match injuries tend to be the most prevalent within elite soccer. ${ }^{1510121416202633}$ However, others have reported that injuries occur equally in matches and training, ${ }^{32}$ while others claim a larger proportion of injuries occur in training than matches. ${ }^{18}$ The latter suggests that players were subjected to a training intensity beyond physical toleration and lacked injury-avoidance skills as well as strength, endurance and coordination. These variables would need to be quantified and used in conjunction with an injury audit to establish the presence of such a relationship.

In the current study, $17 \%$ of injuries were reported from no specified activity. When questioned, players reported the onset of symptoms in the days following training and matches; these were noticeably higher within the U12-14 age group and specifically for the knee. Such findings highlight an injury of gradual onset, and therefore suggest that overuse might be a contributory factor. In order to attribute cause of an injury to a specific session, we suggest that if pain is felt the day after a game, the injury should be recorded as a 'match injury', and likewise for training. This might reduce the numbers of injuries categorised as 'NA', and provide a more accurate injury profile.

The strengths of the current study are that it is the first of its kind to apply the consensus statement ${ }^{7}$ methodology to Premier League academy soccer and categorising players according to exposure. Analysis using standard definitions of injury, matches, training, location of injury and incidence will assist in injury prevention within higher incidence groups, and thus maximise the development time for each individual player. Data were not analysed during the season and so changes to minimise injury were not made, based on the findings.

Limitations of the study include multiple staff recording exposure data, possibly introducing a source of bias. Using fewer staff to monitor and record exposure data in future studies would reduce this. External validity could be improved by increasing the number of Premier League soccer academies. However, although overall injury incidence would be identified and differences between clubs observed, its findings would be limited due to the differing training and coaching methods employed as well as types of matches played. Reporting such data may be difficult given the potential barriers to sharing sensitive data between professional soccer clubs. Perhaps a more useful method would be to perform longitudinal research via data collection from the same academy over several seasons, with additional analysis made with regard to player position and injury incidence.

Certain issues arose surrounding the Injury Record Form throughout the course of data collection, and further amendments might be made. First, in response to the question 'When did the injury occur?' some injuries were reported in the days following an injury and were incorrectly recorded as 'NA'. Rewording the 
section title to 'When was the injury reported?' might allow the researcher to ascertain whether the injury was a result of match or training exposure. Second, in the section 'Indicate type of training or match where injury occurred', it was initially thought that subdividing soccer training into contact and non-contact would provide specific onset details. However, coaching sessions can involve both aspects and to prevent confusion it might be beneficial to group the two options into 'football training'.

\section{CONCLUSION}

This study applied the consensus statement ${ }^{7}$ methodology to Premier League academy soccer and categorise players according to exposure. The data within this study have provided an insight into injuries within elite soccer during the developmental years, which may aid injury prevention. By grouping players according to exposure, the study has allowed accurate results to be produced, which might allow development time to be maximised by highlighting the ages at which elite youth players are susceptible to injury in training and matches.

Acknowledgements The authors are grateful to all staff, Paul Squires (PS), and players from Liverpool Football Club (LFC) for making this research possible.

Contributors AR devised the study, collected the data and assisted in writing the manuscript. PCG assisted in the statistical analysis and writing the manuscript.

Competing interests None declared.

Ethics approval Manchester Metropolitan University.

Provenance and peer review Not commissioned; externally peer reviewed.

Data sharing statement No additional data are available.

Open Access This is an Open Access article distributed in accordance with the Creative Commons Attribution Non Commercial (CC BY-NC 4.0) license, which permits others to distribute, remix, adapt, build upon this work noncommercially, and license their derivative works on different terms, provided the original work is properly cited and the use is non-commercial. See: http:// creativecommons.org/licenses/by-nc/4.0/

\section{REFERENCES}

1. Ekstrand J. Epidemiology of Football Injuries. Sci Sports 2008;23:73-7.

2. Ekstrand J, Karlsson J. The risk of injury in football. There is a need for consensus about definition of injury and the design of studies. Scand J Med Sci Sports 2003;13:147-9.

3. Hodson A. Too much too soon? The risk of 'overuse' injuries in young football players. J Bodyw Mov Ther 1999;3:85-91.

4. MacKay M, Scanlan A, Olsen L, et al. Looking for the evidence: a systematic review of prevention strategies addressing sport and recreational injury among children and youth. J Sci Med Sport 2004; 7:58-73.

5. Price RJ, Hawkins RD, Hulse MA, et al. The Football Association medical research programme: an audit of injuries in academy youth football. Br J Sports Med 2004;38:466-71.

6. Premier League Academy Elite Player Performance Plan. http:// www.premierleague.com/en-gb/youth/elite-player-performance-plan. html (accessed Jan 2016).
7. Fuller C, Ekstrand J, Junge A, et al. Consensus statement on injury definitions and data collection procedures in studies of football (soccer) injuries. Br J Sports Med 2006;40:193-201.

8. Hägglund M, Waldén M, Ekstrand J. Injury incidence and distribution in elite football-a prospective study of the Danish and Swedish top divisions. Scand J Med Sci Sports 2005;15:21-8.

9. Hagglund M, Waldén M, Bahr R, et al. Methods for epidemiological study of injuries to professional football players: developing the UEFA model. Br J Sports Med 2005;39:340-6.

10. Hagglund $M$, Waldén M, Ekstrand J. UEFA injury study-an injury audit of European Championships 2006 to 2008. Br J Sports Med 2009;43:483-9.

11. Junge A, Dvorak J. Soccer injuries: a review on incidence and prevention. Sports Med 2004;34:929-38.

12. Walden M, Hagglund M, Ekstrand J. Injuries in Swedish elite football -a prospective study on injury definitions, risk for injury and injury pattern during 2001. Scand J Med Sci Sports 2005;15:118-25.

13. Dvorak J, Junge A. Football injuries and physical symptoms: a review of the literature. Am J Sports Med 2000;28(5 Suppl):S3-9.

14. Walden M, Hagglund M, Ekstrand J. UEFA Champions League Study: a prospective study of injuries in professional football during the 2001-2 season. Br J Sports Med 2005;39:542-6.

15. Ekstrand J, Hägglund $\mathrm{M}$, Walden $\mathrm{M}$. Epidemiology of muscle injuries in professional football (soccer). Am J Sports Med 2011;39:1226-32.

16. Hawkins RD, Fuller CW. A prospective epidemiological study of injuries in four English professional football clubs. Br J Sports Med 1999;33:196-203.

17. Junge A, Chomiak J, Dvorak J. Incidence of football injuries in youth players. Comparison of players from two European regions. Am J Sports Med 2000;28(5 Suppl):S47-50.

18. Le Gall F, Carling C, Reilly T, et al. Incidence of injuries in elite French youth soccer players: a 10-season study. Am J Sports Med 2006;34:928-38.

19. Nielson $A B, Y$ de J. Epidemiology and traumatology of injuries in soccer. Am J Sports Med 1989;17:803-7.

20. Peterson L, Junge A, Chomiak J, et al. Incidence of football injuries and complaints in different age groups and skill-level groups. Am J Sports Med 2000;28:S51-7.

21. Le Gall F, Carling C, Reilly T. Biological maturity and injury in elite youth football. Scand J Med Sci Sports 2007;17:564-72.

22. Árnason Á, Sigurdsson SB, Gudmundsson A, et al. Risk factors for injuries in football. Am J Sports Med 2004;32:S5-S16.

23. Cloke DJ, Ansell $P$, Avery $P$, et al. Ankle injuries in football academies: a three-centre prospective study. $\mathrm{Br} J$ Sports Med 2011;45:702-8.

24. Cloke DJ, Spencer S, Hodson A, et al. The epidemiology of ankle injuries occurring in English Football Association academies. Br J Sports Med 2009;43:1119-25.

25. von Elm E, Altman DG, Egger M, et al. The Strengthening the Reporting of Observational Studies in Epidemiology (STROBE) Statement: guidelines for reporting observational studies. Ann Intern Med 2007;147:573-7.

26. Ekstrand J, Hägglund $M$, Walden $M$. Injury incidence and injury patterns in professional football-the UEFA injury study. $\mathrm{Br} J$ Sports Med 2011b;45:553-8.

27. Sport Session Planner Ltd. (accessed Jan 2016). http://www. sportsessionplanner.com/

28. Bahr R, Holme I. Risk factors for sports injuries-a methodological approach. Br J Sports Med 2003;37:384-92.

29. Altman DG. Practical statistics for medical research. London: Chapman and Hall, 1991.

30. Szumilas M. Explaining odds ratios. J Can Acad Child Adolesc Psychiatry 2010;19:227-9.

31. Miettinen OS. Standardization of risk ratios. Am J Epidemiol 1972;96:383-8.

32. Deehan DJ, Bell K, McCaskie AW. Adolescent musculoskeletal injuries in a football academy. J Bone Joint Surg Br 2007;89:5-8.

33. Hawkins RD, Hulse MA, Wilkinson $C$, et al. The association football medical research programme: an audit of injuries in professional football. Br J Sports Med 2001;35:43-7.

34. Malina RM. Maturity status and injury risk in youth soccer players. Clin J Sports Med 2010;20:132.

35. Sink EL, Gralla J, Ryba A, et al. Clinical presentation of femoroacetabular impingement in adolescents. J Pediatr Orthop 2008;28:806-11. 